\title{
Electron microscopy study of magnetosomes in a cultured coccoid magnetotactic bacterium
}

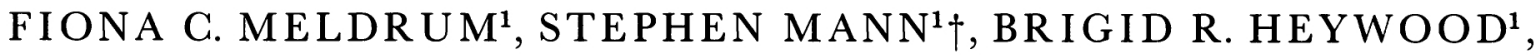 \\ RICHARD B. FRANKEL ${ }^{2}$ AND DENNIS A. BAZYLINSKI ${ }^{3}$ \\ ${ }^{1}$ School of Chemistry, University of Bath, Claverton Down, Bath BA2 7AY, U.K. \\ ${ }^{2}$ Department of Physics, California Polytechnic State University, San Luis Obispo, California 93407, U.S.A. \\ ${ }^{3}$ Department of Chemistry and Chemical Engineering, Stevens Institute of Technology, Castle Point on the Hudson, Hoboken, \\ New Jersey 07030, U.S.A.
}

\begin{abstract}
SUMMARY
Intracellular magnetite $\left(\mathrm{Fe}_{3} \mathrm{O}_{4}\right)$ crystals produced by the magnetotactic bacterium $\mathrm{MC}-1$ were analysed by transmission electron microscopy (TEM). Strain MG-1 represents the first-reported isolation of a coccoid magnetotactic bacterium in axenic culture. The magnetosomes of this bacterium displayed a pseudo-hexagonal prismatic habit, were elongated along the $\langle 111\rangle$ crystallographic direction, and were truncated by $\{111\},\{100\}$ and $\{110\}$ faces. The presence of $\{111\}$ truncations represents a modification of the magnetosome morphology previously determined for those in other coccoid bacteria. Study of immature crystals produced by strain MC-l showed that the crystal morphology was controlled even at early stages of development. Changes in the culture media affected both the number and shape of the bacterial magnetite crystals. Cells grown in an acetate-containing medium contained on average more crystals than those in cells grown in a sulphide-containing medium. Crystals synthesized in the acetategrown cells tended to be less truncated than those in the sulphide-grown cells. No iron sulphide minerals, such as greigite, were observed in cells grown in the presence of sulphide.
\end{abstract}

\section{INTRODUCTION}

Magnetotactic bacteria are characterized by their ability to synthesize intracellular magnetite $\left(\mathrm{Fe}_{3} \mathrm{O}_{4}\right)$ (Mann et al. 1991; Mann \& Frankel 1989), greigite $\left(\mathrm{Fe}_{3} \mathrm{~S}_{4}\right.$ ) (Heywood et al. 1990), or a combination of greigite and pyrite $\left(\mathrm{FeS}_{2}\right)$ (Mann et al. 1990). Alignment of these magnetosomes within a bacterium endows the cell with a net magnetic dipole which gives rise to a tactic response to the direction of the geomagnetic field. Although a range of morphologically diverse species of magnetotactic bacteria have been located in freshwater and marine habitats worldwide, the isolation and subsequent culture of individual species has not been readily achieved, owing to the difficulty in recreating the specific microenvironments necessary for bacterial propagation and crystal growth (Spormann \& Wolfe 1984; Blakemore et al. 1985). Here we describe a chemical and an electron microscopic (EM) analysis of the magnetosomes of a coccoid bacterium, designated strain MC-1. Strain MC-1 represents the first successful isolation of a coccoid species of magnetotactic bacteria in axenic culture. Cells of this species are Gram-negative and highly motile, moving by means of two flagellar bundles. The organism is superficially similar to Bilophococcus magnetotacticus, which has not yet been isolated in pure culture but was described in some detail by Moench (1988). The influence of the culture medium on the production of magnetosomes by MC-1 was investigated by comparing crystals produced in cells grown in sulphide-oxygen and acetate-oxygen gradients.

\section{MATERIALS AND METHODS}

Strain MC-1 was isolated from water collected from the Pettaquamscutt Estuary, Rhode Island, U.S.A. Bacteria were grown in semi-solid oxygen gradient cultures of two types (D. A. Bazylinski, unpublished data). Although chemoautolithotrophy has not been determined in this species, cells were grown under these conditions in a sulphide-oxygen double gradient, with sulphide as the energy source, and with sodium bicarbonate included in the growth medium as the sole carbon source. In addition, cells were also grown chemoheterotrophically in oxygen-gradient cultures with acetate as the carbon and presumed energy source. Cells were grown until microaerophilic bands of cells formed in the culture tubes and were removed with sterile syringes.

All microscopy was done using a JEOL 2000FX transmission electron microscope (TEM), fitted with a Link windowless elemental dispersive X-ray (EDX) detector and operating at $200 \mathrm{kV}$ with a maximum point to point resolution of $0.28 \mathrm{~nm}$. The bacteria were supported on $\mathrm{Ni}$ TEM grids. Low-magnification studies and EDX analysis were done on intact bacteria. Data on crystal sizes and numbers 


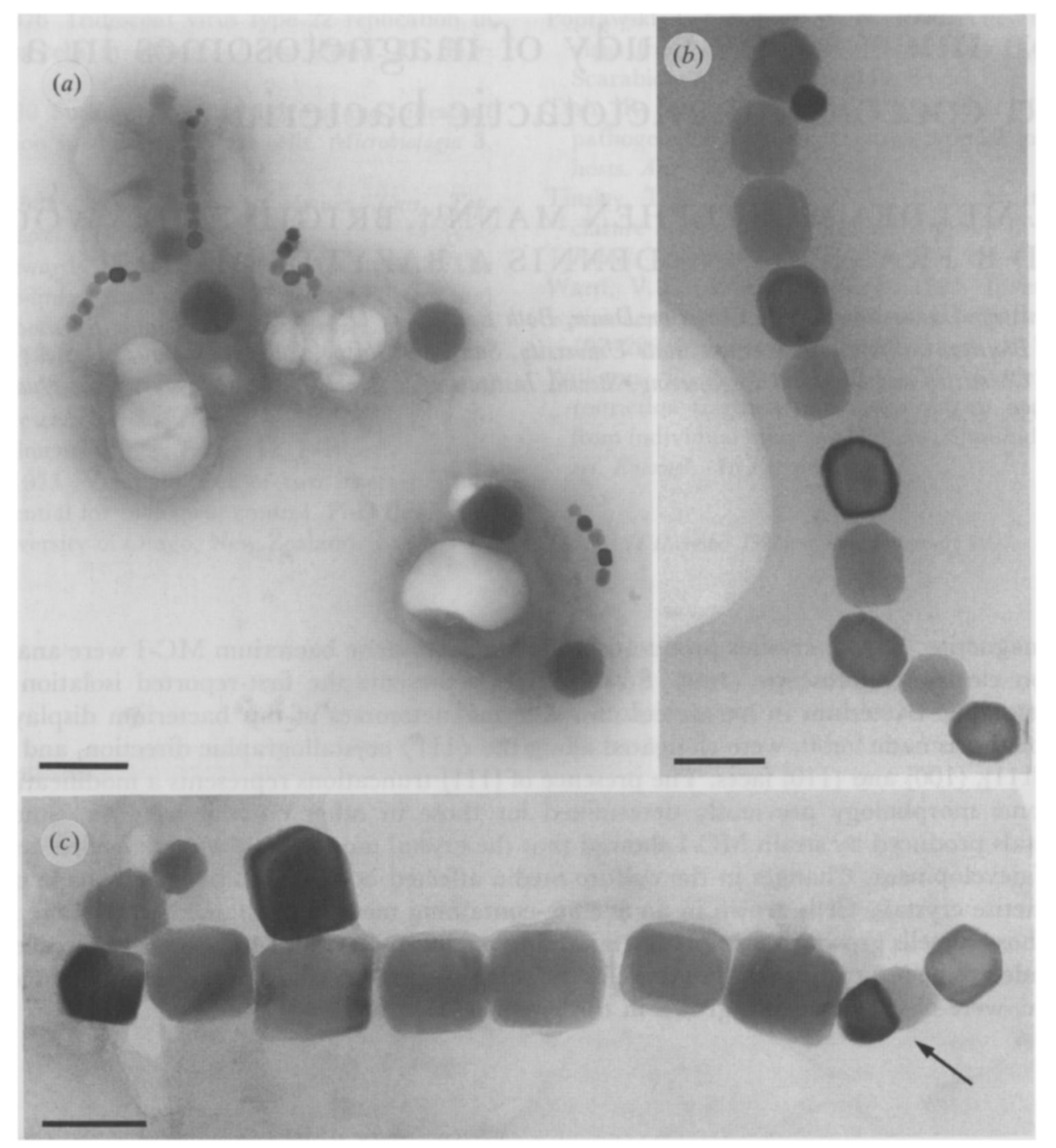

Figure 1. (a) Low-magnification micrograph of cells of strain MC-1 grown in a sulphide gradient showing intracellular chains of magnetite crystals. Bar $=500 \mathrm{~nm}$. $(b)$ Chain of magnetite crystals in a MC-1 cell grown in the presence of sulphide. Note the well-defined truncated prismatic morphology. Bar $=100 \mathrm{~nm}$. (c) Chain of magnetite crystals in a MC-1 cell grown in the presence of acetate showing rectangular crystals with minor truncations. Arrow shows a twinned crystal. Bar $=100 \mathrm{~nm}$.

were averaged over a population of 100 bacteria for both acetate and sulphide-based cultures. The sample grids of bacteria grown in the acetate gradient were treated with $1 \%$ (by volume) hypochlorite solution before recording highresolution lattice images because the quantity of organic matter associated with some bacteria greatly reduced image resolution. High-resolution TEM (HRTEM) images were recorded at a magnification of $\times 500000$ using an objective aperture of $80 \mu \mathrm{m}$. The lattice fringe spacings measured from micrographs were corrected according to a calibration done on the microscope by using a gold foil at a magnification of $\times 500000$ and a voltage of $200 \mathrm{kV}$. The fringe spacings were indexed by comparison with published data for magnetite: space group $\mathrm{Fd} 3 \mathrm{~m}$, with lattice parameter $a=0.8394 \mathrm{~nm}$.

\section{RESULTS}

(a) Low-magnification studies

Low-magnification studies of the coccoid cells grown in both sulphide-oxygen and acetate-oxygen gradient media showed a single linear chain of intracellular anisotropic magnetite-containing magnetosomes associated with individual bacteria (figure 1). Iron
Table 1. Statistical data for magnetosomes produced by $M C-1$ cells grown in a sulphide gradient

\begin{tabular}{|c|c|c|c|}
\hline & mean & $\begin{array}{l}\text { standard } \\
\text { deviation }\end{array}$ & range \\
\hline $\begin{array}{l}\text { number of crystals per } \\
\text { bacterium }\end{array}$ & 10 & 2 & $6-15$ \\
\hline length/nm & 72 & 11 & 33-95 \\
\hline width/nm & 70 & 13 & $29-87$ \\
\hline aspect ratio & 1.2 & 0.2 & - \\
\hline
\end{tabular}

sulphides, such as greigite, were not observed in cells grown with sulphide. The average number of magnetite crystals per chain was increased in the acetategrown cells as compared with the sulphide-based media (tables 1 and 2). In both samples, the mature crystals appeared in projection as truncated rectangles whereas the immature magnetosomes, located at one or occasionally both ends of the crystal chain, were approximately isotropic in morphology. The mature crystals in MC-1 cells grown with sulphide were 

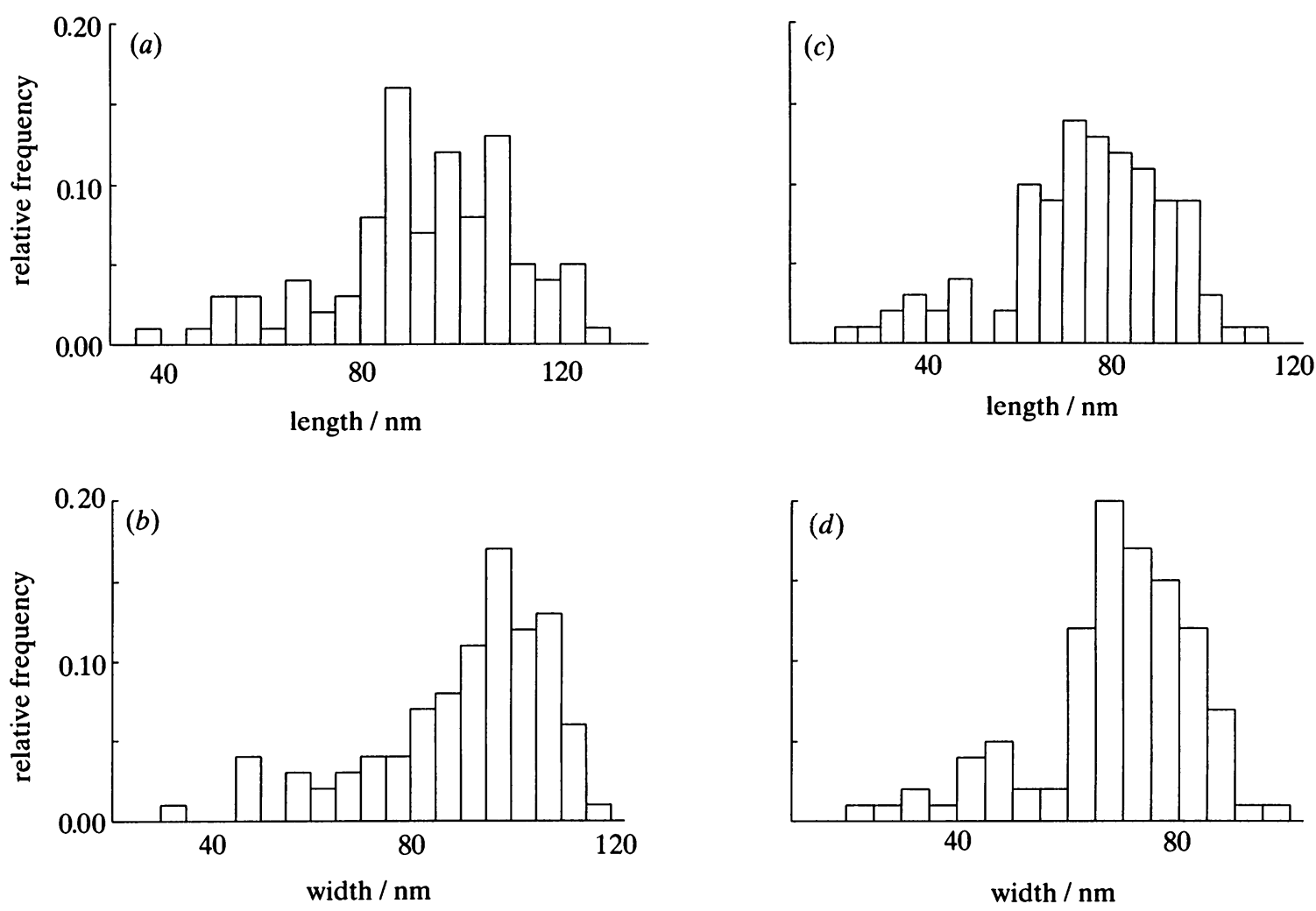

Figure 2. Histograms of particle length and width in MG-1 cells grown in $(a, b)$ acetate- and $(c, d)$ sulphide-based media.

Table 2. Statistical data for magnetosomes produced by $M C-1$ cells grown in an acetate gradient

\begin{tabular}{|c|c|c|c|}
\hline & mean & $\begin{array}{l}\text { standard } \\
\text { deviation }\end{array}$ & range \\
\hline $\begin{array}{l}\text { number of crystals per } \\
\text { bacterium }\end{array}$ & 14 & 3 & $8-19$ \\
\hline length/nm & 83 & 14 & $30-110$ \\
\hline width/nm & 78 & 11 & $15-107$ \\
\hline aspect ratio & 1.2 & 0.1 & - \\
\hline
\end{tabular}

generally more truncated than those in the acetategrown cells (figure 1). The latter were almost rectangular except for minor truncations at the vertices, whereas the former had marked truncations and often rounded corners and ends.

The mean length and width of magnetosomes formed in MC-1 cells grown with acetate was greater than in those grown with sulphide, although the aspect ratios were similar for crystals of length greater than $40 \mathrm{~nm}$ (figure 2, tables 1 and 2). Twinned crystals were observed in both sulphide- and acetate-grown cells, as recognized by a change in diffraction contrast between the two halves of the particle (figure $1 c$ ). The twin plane was identified as the $\{111\}$ crystal plane by highresolution imaging, and was invariably located in the centre of the crystal in an orientation perpendicular to the morphological long axis. Growth faults, resulting in perturbation of the prismatic morphology, were observed in some of the magnetosomes of the acetategrown cells and to a lesser degree in the sulphidegrown bacteria.

\section{(b) High-resolution studies}

To ascertain the structural and morphological details of the MC-1 magnetosomes, lattice imaging studies were undertaken on crystals present within cells mounted onto the EM grid. In all cases, the crystals gave lattice spacings and angles consistent with stoichiometric magnetite.

\section{(c) Sulphide-grown MC-1 magnetite crystals}

Combinations of $\{200\},\{400\},\{111\},\{311\}$ and $\{220\}$ lattice fringes were resolved on many magnetite crystals, and faces parallel to $\{111\},\{220\}$ and $\{200\}$ planes were identified (figure 3 ). Although several approximately isotropic crystals were viewed, most displayed an elongation, which was without exception along a $\langle 111\rangle$ direction. Crystals were observed lying in both $\langle 110\rangle$ and $\langle 211\rangle$ zones, with the $\langle 110\rangle$ orientation being more common. In this zone, the crystals appeared centrosymmetric and were capped by $\{111\}$ faces with $\{100\}$ and $\{110\}$ truncations of variable importance. The long side faces appear illdefined because they do not lie parallel to the $\{110\}$ zone of projection. In the $\langle 211\rangle$ zone, these faces appeared as well-defined straight edges lying parallel to faces of $\{110\}$ form. These results show that the crystal morphology is based on a hexagonal prism of $\{110\}$ faces capped by $\{111\}$ faces and truncated by $\{100\}$ and $\{110\}$ faces.

No dislocations were observed in any of the crystals imaged. However, some crystals did show marked variations in contrast, which were considered to 


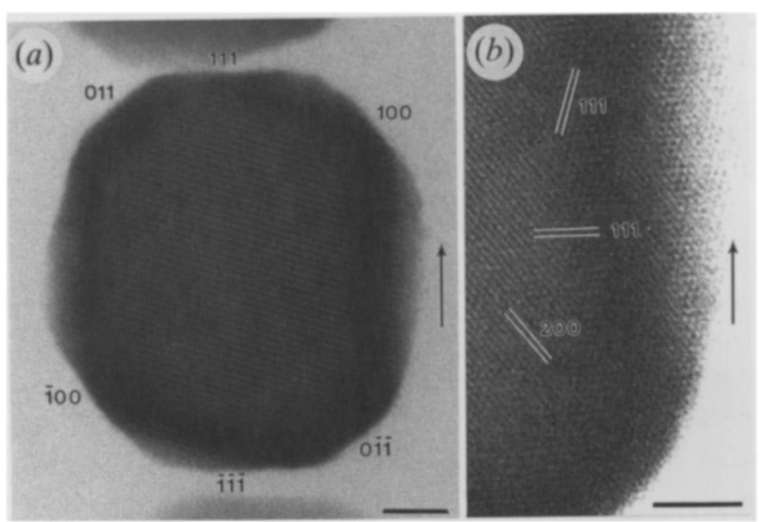

Figure 3. High-resolution image of a magnetite crystal from a MC-1 cell grown with sulphide. (a) Single crystal oriented along the [011] direction with identified crystal faces. Arrow indicates the direction of [111] elongation. Bar $=10 \mathrm{~nm}$. (b) Enlarged image of part of the crystal shown in $(a)$. Lattice fringes corresponding to two sets of $\{111\}$ planes and one set of $\{200\}$ planes are shown. Bar $=5 \mathrm{~nm}$.
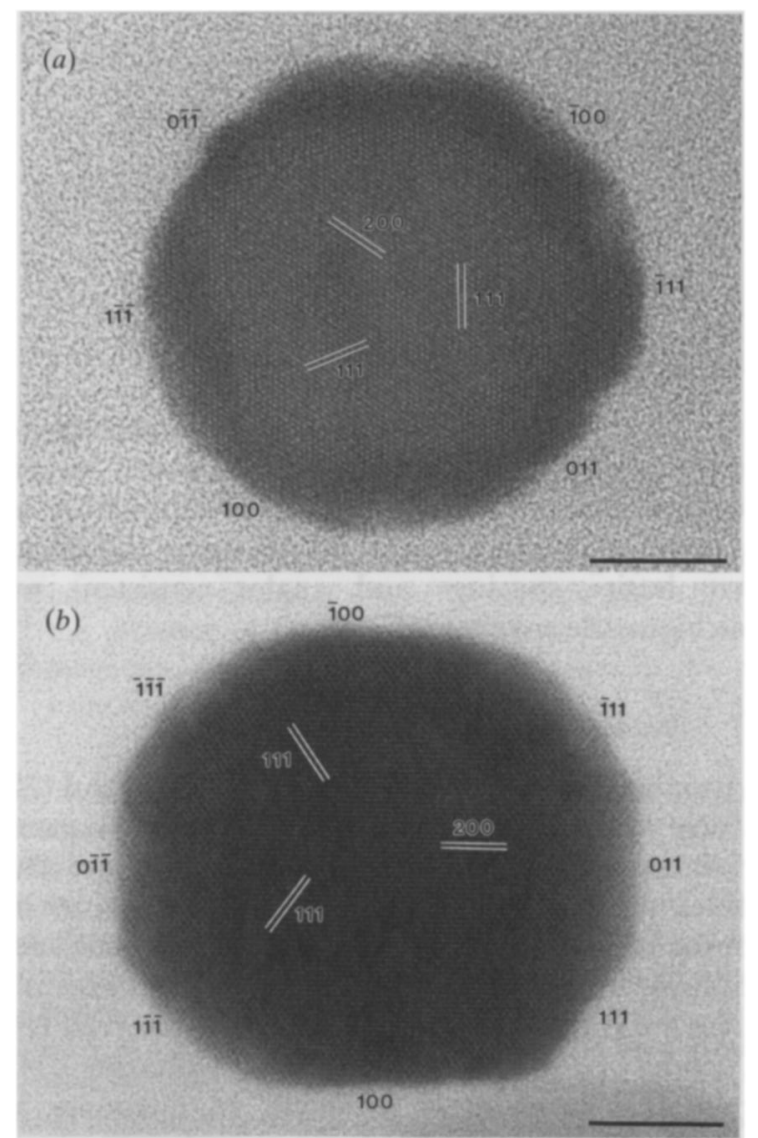

Figure 4. High-resolution image of immature magnetite crystals from MC-1 cells grown with sulphide. Both crystals are oriented along [0ㅣㄹ and show two sets of $\{111\}$ planes and one set of $\{200\}$ planes. (a) Spherical single crystal with no well-defined crystal faces. Bar $=10 \mathrm{~nm}$. (b) Single crystal with developing faces. $B a r=10 \mathrm{~nm}$.

originate from macro-steps on the crystal surface, rather than from discontinuities in the crystal lattice.

Figure $4 a, b$ shows high-resolution images of immature crystals from MC-1 cells grown in sulphide gradients. The immature magnetosomes were single

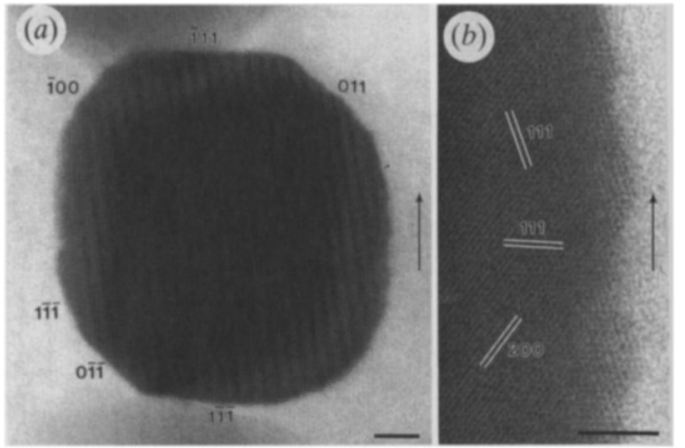

Figure 5. High-resolution image of a magnetite crystal from a MC-1 cell grown with acetate in the absence of sulphide. (a) Single crystal oriented along the [011] direction with identified crystal faces. Arrow indicates the direction of [111] elongation. Bar $=10 \mathrm{~nm}$. $(b)$ Enlarged image of part of the crystal shown in $(a)$. Lattice fringes corresponding to two sets of $\{111\}$ planes and one set of $\{200\}$ planes are shown. Bar $=5 \mathrm{~nm}$

crystals of magnetite but, unlike the mature crystals, they displayed isotropic morphologies and were more circular in projection. However, there was some evidence of developing truncations; for example, figure $4 b$ shows well-defined truncations on a crystal only $35 \mathrm{~nm}$ in diameter. Both immature magnetosomes in figure 4 show the same multiple sets of fringes corresponding to the $\langle 110\rangle$ zone. However, although they are oriented along the same crystallographic direction, they appear to be developing different combinations of $\{111\},\{100\}$ and $\{110\}$ faces. Presumably, the local biological conditions of magnetosome formation, as well as the environmental régime set by the culture conditions, have a key role to play in the development of individual crystals.

\section{(d) Acetate-grown MC-1 magnetite crystals}

The increased size and thickness of magnetite crystals produced by MC-1 cells grown with acetate reduced the number of lattice images containing multiple sets of fringes. As for the sulphide-grown cells, lattice fringes corresponding to the $\{111\},\{220\}$ and $\{200\} d$ spacings and their associated crystal faces were observed. Most crystals were imaged in the $\langle 110\rangle$ zone but several were also imaged along the $\langle 211\rangle$ direction. Mature crystals were elongated along the $\langle 111\rangle$ direction and contained small $\{100\},\{110\}$ and (less frequently) $\{111\}$ truncations (figure 5). The immature magnetosomes were isotropic single crystals with no distinctive morphology (figure 6).

\section{DISGUSSION}

Cells of strain MC-1 produced only magnetite and not iron sulphides such as greigite whether they were cultured in the presence of sulphide or not. This suggests that the chemical composition of the mineral phase of the magnetosomes is species or strain specific. This is supported by phylogenetic analysis of magnetite- and iron sulphide-producing magnetotactic bacteria (DeLong et al. 1993). 


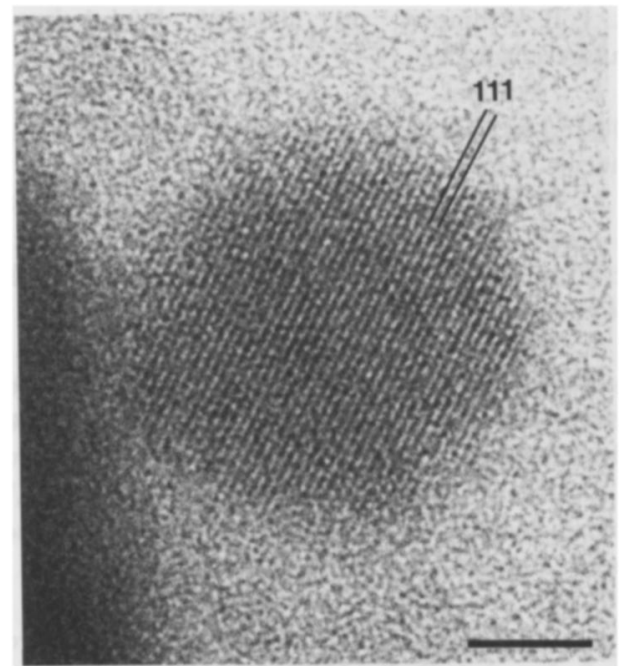

Figure 6. High-resolution image of an immature magnetite crystal from a MC-1 cell grown with acetate. The crystal is isotropic and ill-defined. One set of $\{111\}$ planes are observed. Bar $=5 \mathrm{~nm}$.

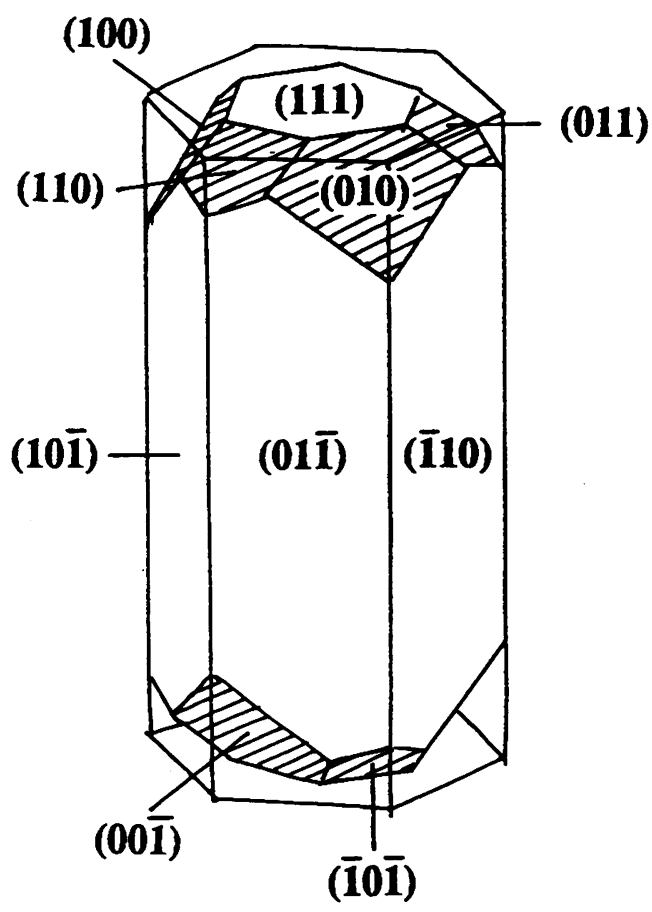

Figure 7. Drawing showing the idealized morphology of intracellular magnetite crystals synthesized by MC-1 cells.

The idealized morphology of magnetosomes produced by cells of strain MC-1 grown in acetate- and sulphide-based cultures is shown in figure 7. Previous studies of bacterial magnetite synthesized by uncultured coccoid cells gave the same result (Mann et al. $1984 b$ ). However, the use of cultured organisms has shown that modifications to the crystal morphology are possible, depending on the chemical composition of the culture medium. Thus, whereas the crystals of the sulphide-grown cells approximate to the idealized morphology, those of the acetate-grown cells show more variation. The results suggest that the differences in magnetosome production and morphology between acetate- and sulphide-grown cells arise from an increased growth rate of the coccus cells in acetate medium. The slow growth of crystals results in the expression of well-defined faces such as observed in the sulphide-based culture. The characteristic morphology of the MC-1 magnetosomes is obscured to some extent in the acetate-grown cells, presumably because the crystals are synthesized more rapidly and therefore become more ill-defined, often with loss of the truncated faces. Indeed, rapidly precipitated synthetic magnetites show an approximately spherical morphology and roughened faces (Mann et al. 1989). This is exemplified by the small, irregular and crystallographically ill-defined magnetite particles produced by bacterial strain GS-15 (Sparks et al. 1990). This dissimilatory, non-magnetotactic, iron-reducing bacterium induces the precipitation of extracellular magnetite under anaerobic conditions. The minimal control imposed on extracellular biomineralization in GS15 compared with the intracellular process in MC-1 cells is clearly reflected in the differences in the crystal chemical specificity of the mineral product.

The fact that no major alteration occurred in the expression of the unusual hexagonal prismatic morphology of MC-1 bacterial magnetite on changing culture conditions suggests that crystal synthesis is primarily under genetic control. Bacterial magnetites are produced within intracellular vesicles (Gorby et al. 1988) which may control the chemical, interfacial and spatial aspects of mineralization (Mann \& Frankel 1989). In particular, the characteristic 〈111〉 elongation observed in crystals formed in MG-1 cells is contrary to the crystallographic cubic symmetry suggesting that the synthesis and assembly of the vesicular ultrastructure is a key component in determining the particle morphology.

The morphology of the early MG-1 crystals is markedly different from the immature crystals viewed in cells of an unidentified ovoid-shaped bacterium containing bullet-shaped crystals (Mann et al. $1987 a, b)$ and in the cultured magnetotactic bacteria Aquaspirillum magnetotacticum (Mann et al. 1984a). The bullet-shaped magnetosomes produced by the ovoidshaped cells develop from cubo-octahedral crystallites, with this morphology being apparent in crystals as small as $15 \mathrm{~nm}$. Thus, a definite geometry is displayed at earlier stages of crystal growth in the ovoid-shaped bacteria as compared with that in cells of strain MC1. Importantly, the immature crystallites in strain MC1 do not conform to a cubo-octahedral morphology. The bacteria act to control crystal morphology even at the early stages of crystal growth, as indicated by the expression of $\{110\}$ faces which are not usually observed in synthetic magnetites grown from aqueous solution. The apparently spherical morphology of immature crystals of strain MC-1 is characteristic of crystals grown under a kinetic régime in which the initial stages of growth of the magnetosome nuclei are reasonably fast. Further crystal development is probably slower and proceeds with specific stabilization of the $\{110\}$ faces along with the low energy $\{111\}$ and $\{100\}$ surfaces.

In conclusion, this study demonstrates that the cultured coccoid bacterium, strain MG-1, produces 
intracellular magnetite crystals and not iron sulphides, even when grown in the presence of sulphide, that are comparable in size and morphology with those previously described for another coccoid magnetotactic bacterium (Mann et al. 1984b). High-resolution imaging of immature magnetosomes showed that the organism exerts control over crystal development at early stages of crystal growth. Comparison of the crystals formed by MC-1 when cultured with sulphide and acetate gradients showed some differences in the crystal size and morphology, which were attributed to different crystal growth rates in these chemical media.

R.B.F. and D.A.B. were supported by the U.S. Office of Naval Research grant ONR N00014-91-J-1290 and also by the U.S. National Science Foundation grant MCB-9117694. S.M. thanks the SERC for support of a postgraduate studentship (F.C.M.) and BP Research for postdoctoral funds (B.R.H.).

\section{REFERENCES}

Blakemore, R. P., Short, K. A., Bazylinski, D. A., Rosenblatt, C. \& Frankel, R. B. 1985 Microaerobic conditions are required for magnetite formation within Aquaspirillum magnetotacticum. Geomicrobiol. J. 4(1), 53-71.

DeLong, E. F., Frankel, R. B. \& Bazylinski, D. A. 1993 Multiple evolutionary origins of magnetotaxis in bacteria. Science, Wash. 259, 803-806.

Gorby, Y. A., Beveridge, T. J. \& Blakemore, R. P. 1988 Characterization of the bacterial magnetosome membrane. J. Bact. 170, 834-841.

Heywood, B. R., Bazylinski, D. A., Garrett-Reed, A., Mann, S. \& Frankel, R. B. 1990 Controlled biosynthesis of greigite $\left(\mathrm{Fe}_{3} \mathrm{~S}_{4}\right)$ in magnetotactic bacteria. Naturwissenschaften 77, 536-538.

Mann, S. \& Frankel, R. B. 1989 Magnetite biomineralization in unicellular microorganisms. In Biomineralization: chemical and biochemical perspectives (ed. S. Mann, J. Webb
\& R. J. P. Williams), pp. 389-426. Weinheim: VCH Verlagsgesellschaft.

Mann, S., Frankel, R. B. \& Blakemore, R. P. $1984 a$ Structure, morphology and crystal growth of bacterial magnetite. Nature, Lond. 310, 405-407.

Mann, S., Moench, T. T. \& Williams, R.J. P. $1984 b$ A high resolution electron microscopic investigation of bacterial magnetite: implications for crystal growth. Proc. R. Soc. Lond. B 221, 385-393.

Mann, S., Sparks, N. H. C. \& Blakemore, R. P. $1987 a$ Ultrastructure and characterization of anisotropic magnetite crystals in magnetotactic bacteria. Proc. R. Soc. Lond. B 231, 469-476.

Mann, S., Sparks, N. H. C. \& Blakemore, R. P. $1987 b$ Structure, morphology and crystal growth of anisotropic magnetite crystals in magnetotactic bactcria. Proc. R. Soc. Lond. B 231, 477-487.

Mann, S., Sparks, N. H. C., Couling, S. B., Larcombc, M. C. \& Frankel, R. B. 1989 Crystallochemical characterization of magnetic spinels prepared from aqueous solution. J. chem. Soc. Faraday Trans. I 85(9), 3033-3044.

Mann, S., Sparks, N. H. C., Frankel, R. B., Bazylinski, D. A. \& Jannasch, H.W. 1990 Biomineralization of ferrimagnetic greigite $\left(\mathrm{Fe}_{3} \mathrm{~S}_{4}\right)$ and iron pyrite $\left(\mathrm{FeS}_{2}\right)$ in a magnetotactic bacterium. Nature, Lond. 343, 258-261.

Mann, S., Sparks, N. H. C. \& Board, R. G. 1991 Magnetotactic bacteria: microbiology, biomineralization, palaeomagnetism and biotechnology. Adv. microb. Physiology 31, 125--181.

Moench, T. T. 1988 Bilophococcus magnetotacticus gen. nov. sp. nov., a motile magnetic coccus. Antonie van Leeuwenhoek 54, 483-496.

Sparks, N. H. G., Mann, S., Bazylinski, D. A., Lovely, D. R., Jannasch, H. W. \& Frankel, R. B. 1990 Structure and morphology of magnetite formed by a marine magnetotactic bacterium and dissimilatory iron-reducing bacteria. Earth planet. Sci. Lett. 98, 14-22.

Spormann, A. M. \& Wolfe, R. S. 1984 Chemotactic, magnetotactic and tactile behaviour in a magnetic spirillum. FEMS microbiol. Lett. 22, 171177. 